\title{
Body composition and specific and general strength indices as predictors of 100-m front crawl performance
}

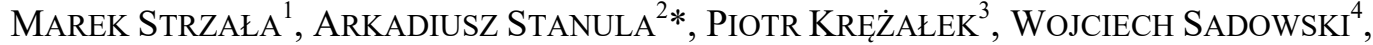 \\ ROBERT WILK ${ }^{4}$, TOMASZ PAŁKA ${ }^{5}$, KAMIL SOKOŁOWSKI $^{6}$, ARTUR RADECKI-PAWLIK ${ }^{7}$ \\ ${ }^{1}$ Department of Water Sports, Faculty of Physical Education and Sport, \\ University School of Physical Education in Krakow, Kraków, Poland. \\ ${ }^{2}$ Institute of Sport Science, Department of Swimming and Water Rescue, \\ The Jerzy Kukuczka Academy of Physical Education, Katowice, Poland. \\ ${ }^{3}$ Department of Physiotherapy, University School of Physical Education in Krakow, Kraków, Poland. \\ ${ }^{4}$ Department of Swimming and Water Rescue, The Jerzy Kukuczka Academy of Physical Education, Katowice, Poland. \\ ${ }^{5}$ Department of Physiology and Biochemistry; Faculty of Physical Education and Sport, \\ University of Physical Education in Krakow, Kraków, Poland. \\ ${ }^{6}$ University School of Physical Education in Krakow, Kraków, Poland. \\ ${ }^{7}$ Faculty of Civil Engineering, Cracow University of Technology, Kraków, Poland.
}

\begin{abstract}
Purpose: The purpose of this research was to examine the impact of body composition on the anaerobic ability to generate strength and power produced separately by upper and lower limbs during dry-land and in-water (propulsion force) tests. Further examination included the influence of all gathered anaerobic strength indices on the results of 100-m front crawl race. Methods: The study involved 26 male swimmers (age: $19.8 \pm 2.48$ years). Fat-free mass, total body water and muscle mass of arms, legs, and trunk were measured. Dry-land average work, maximal power generated in 40-second arm-cranking test, and work generated in 20 countermovement jumps were evaluated. The forces generated separately by arms and legs were assessed during 40 -second tethered swimming. All indices of body composition were found strongly correlated with indices of average work and maximal power generated by arms and legs in dryland tests. Results: Muscle mass of arms and trunk moderately and strongly $(r=0.44-0.64)$ influenced the force generated by arms in tethered swimming. There was no significance in the relationship of leg muscle mass and force generated by legs in tethered swimming. Significant relationships were observed between the results of the 100-m front crawl and the muscle mass of the arms, trunk, legs, as well as the average work and maximal power in the arm-cranking test $(r: 0.39-0.54)$. The average impulse of arm force and maximal leg force in tethered swimming moderately and significantly correlated with $100-\mathrm{m}$ swimming results. Conclusions: The study concludes the relevance of developing muscle mass balanced to the body size, which is involved in propulsion force production in sprint front crawl swimming.
\end{abstract}

Key words: swimming, strength, power, movement velocity, biomechanics, body composition

\section{Introduction}

In short distance competitive swimming, the ability to generate propulsion depends on muscle strength and power properties. These properties, in turn, are related to body composition, lean body mass, and especially, muscle mass. Muscle mass seems to be logically correlated with a high level of strength and propulsion generation, and thus with swimming speed. This interplay usually occurs in competitive swimming [16], [18] if the increased muscle mass does not cause excessive increase in body size, reducing its slenderness and, therefore, increasing frontal and form drag [4], [17]. Swimmers of each gender are similar in their overall body structure, and even a slight differ-

\footnotetext{
* Corresponding author: Arkadiusz Stanula, The Jerzy Kukuczka Academy of Physical Education, ul. Mikołowska 72a, 40-065, Katowice, Poland, Phone: 004832 2075105, e-mail: a.stanula@awf.katowice.pl

Received: May 29th, 2020

Accepted for publication: September 3rd, 2020
} 
ence in their anthropometric variables, e.g., height, weight or muscle mass, can alter their performance [4]. Thus, some of the anthropometric variables can be helpful in selecting the most suitable swimming distance for a given swimmer in order to increase the likelihood of success in competition. The importance of body structure and muscle mass in swimming performance is clearly reflected when sex-related difference in swimming performance is observed. Nutrition and training of swimmers, just like athletes in other sports, play key role in developing muscle size and improving lean body mass, which enhances performance [18]. Similarly, Pyne et al. [16] found an increase in lean body mass within season (from midseason or pre-taper to taper phase) and between seasons (years). The study by Roelofs et al. [18] concludes that upper body musculature greatly contributes to force production and propulsion in swimming, which, together with other studies on lean body mass [16] or arm muscle area estimations in combination with the development of propulsive force during swimming, provides a premise for further observation in this field [2], [19].

The relationship between general strength and conditioning of upper limbs [9] and lower limbs [3], [10], [23], [25] and swimming performance has been confirmed by many studies. Propulsive force or power was determined as a predictor of swimming performance in other observations [1], [11]-[12], [15], [20]. Most of them showed a valid correlation between the maximal force generated by stroking arms or whole body and swimming speed in the shortest sprint events. However, over longer distances, it is average force generation or endurance that plays a key role, where efficient generation of energy and disposal of metabolites are priorities [21].

In front crawl sprints, the propulsion function of the legs [6], [12] and their role in body stabilization is important, although their share in whole propulsion production may be little [5], [24]. Therefore, too intensive use of legs can be energetically unfavourable [5]. Nevertheless, separate measurements of arm and leg thrust outputs during different swimming conditions may be advantageous for well-shaped training programs, for ongoing, systematic evaluation of strength preparation in developing talents, and also for talent identification. Similar suggestions were put forward in several lately conducted studies by $\mathrm{Ng}$, Wen Yam, Lum, and Barbosa [14], and Morouço et al. [11] after their experiments regarding tethered whole body, front crawl arms only, or flutter kick swimming.

The purpose of this research was to examine: (a) the impact of body composition (muscle mass, fat-free mass, and total body water) on the anaerobic ability to generate strength and power, separately by upper and lower limbs, during dry-land exercises, such as arm cranking and countermovement jumps, in competitive swimmers; (b) the impact of body composition indicators on the anaerobic ability to generate thrust separately with the upper and lower limbs during front crawl arms only tethered swimming and tethered flutter kick, using partly newly designed swimming tests; (c) the influence of body composition indicators on front crawl 100-m trial.

We also intended to examine the relationship between a $100-\mathrm{m}$ trial performance and thrust results for in-water tests and dry-land strength indices.

We expected that body composition indices and the specific in-water tests results would be good predictors of sprint front crawl swimming (100-m trial performance).

\section{Methods}

\section{Experimental approach to the problem}

The issue of the impact of muscle mass on the ability to produce strength and propulsion in swimmers, in whom slenderness, flexibility, and range of motion in the joints are priorities of body shape and function, has been addressed. We examined the predicted muscles of the whole body and of upper and lower limbs and torso separately. We focused on the relationship of these indicators and the general ability to produce strength and power in dry-land and propulsion force in specific water conditions, at the same time determining the impact of strength and power indicators on the results of sprint swimming.

\section{Participants}

A total of 26 male swimmers volunteered in this study: 8 from a high school, specialized in swimming, and 18 from two university swimming clubs in Poland. The participants' mean age, height, body mass, and body mass index (BMI) were: $19.8 \pm 2.48$ years (range: $17-25$ years), $183.8 \pm 6.44 \mathrm{~cm}, 77.2 \pm 9.51 \mathrm{~kg}$, and 22.78, respectively. All subjects took part in most of the top-ranked open category swimming meets in Poland. All of them were healthy and had licenses from the Polish Swimming Federation. Of the 26 swimmers, 4 participated in regional meets, 18 in national meets, and 4 were experienced in international tournaments. Their personal best results at these 3 levels of competition in 100-m freestyle were: $79.6 \%, 87.6 \%$, and $92.6 \%$, respectively (expressed as a percentage of the 
world record). The swimmers participated in 2 training sessions a day, 6 days a week. The study was approved by the University Ethics Committee at the Jerzy Kukuczka Academy of Physical Education in Katowice on April 19, 2018, which consented to the conduct of the research as confirmed by Resolution No. $7 / 2018$.

\section{Analysis of body composition}

Segmental body composition was estimated by using the Tanita BC-418 body composition analyser (Tokyo, Japan). Prior to the measurement, basic data and body type of the athlete under examination were entered in the panel of the analyser. The electrode surfaces, contacting the subjects' skin, were cleaned before each measurement. The participant stepped barefoot on the analyser base when the device was ready. Both feet were in contact with the electrode plates. Then he held the hand grips with embedded electrodes, and a low voltage current flowed through the body. The measurements in all subjects were carried out in a temperature- and humidity-controlled room. The data obtained in each measurement were: body mass (BM, kg), fat-free mass (comprised of muscle, bone, organ tissue, water, and all other fatfree mass in the body) (FFM, kg), total body water (TBW, kg), and predicted muscle mass for specific body parts: arms ( $m_{m}$ arms, $\left.\mathrm{kg}\right)$, legs $\left(m_{m}\right.$ legs, $\left.\mathrm{kg}\right)$, and trunk $\left(m_{m}\right.$ trunk, $\left.\mathrm{kg}\right)$. The FFM and TBW were also expressed as a percentage of BM.

\section{Dry-land maximal anaerobic power}

A 40-second upper extremity test, the arm-crank, was performed in a sitting position, with the use of the custom designed ergometer (834E-Ergomedic, Monark, Sweden). The ergometer braking force was set for each individual at $4.5 \% \mathrm{BM}$. Average power of arms: $P_{\text {cra }}[\mathrm{W}]$ as well as maximal power generated by arms: $P_{\text {cra max }}[\mathrm{W}]$ were measured during this test. Also, the values of these indices in relation to $\mathrm{BM}$ were calculated and analysed: $P_{\text {cra rel }}\left[\mathrm{W} \cdot \mathrm{kg}^{-1}\right]$ and $P_{\text {cra rel max }}\left[\mathrm{W} \cdot \mathrm{kg}^{-1}\right]$.

The lower extremity test was a series of 20 countermovement jumps $(20 \mathrm{CMJ})$ performed on a force plate (AMTI BP 400600, USA) rigidly fixed to the laboratory floor. The frequency of jumps was imposed by using metronome - 1 jump in every 2 seconds. At the beginning of the test, the athlete stood upright on the platform with the weight evenly distributed over both feet. Hands were placed on the hips throughout the test to eliminate their contribution to energy generation. Work generated in a single jump $-W_{\mathrm{CMJ}}[\mathrm{J}]$ - averaged over the 20 jumps, was taken as an abso- lute indicator of anaerobic muscle system motor capabilities. Average elevation of the centre of mass $-h[\mathrm{~cm}]$ - in the 20 jumps was considered as an indicator of muscle system motor capabilities relative to BM.

The arm-cranking test and the $20 \mathrm{CMJ}$ test were preceded by 15 -minute warm-ups at the intensity of approximately $50 \%$ of maximal oxygen uptake, with a changing movement rhythm.

\section{Tethered swimming}

A 40-second all-out front crawl stroking was performed on a tether in a water flume to test the upper extremities. The water flume (flowing water) was used to avoid conditions in which the propulsive stroking of the arms would be different than during free swimming. To ensure adequate buoyancy of the lower limbs, the swimmer was equipped with two buoys, placed between the thighs and ankles. Additionally, to prevent the buoys from falling out, the swimmers' ankles were wrapped with adhesive tape. The swimmer was connected to a steel pole with a $5.65-\mathrm{m}$ steel cable (with a waist belt) and a dynamometer (recording at $100 \mathrm{~Hz})$ (Fig. 1). The point of fixing the dynamometer to the pole was $0.49 \mathrm{~m}$ above the water surface. The flow velocity of water in the swimming flume was set to $0.9 \mathrm{~m} \cdot \mathrm{s}^{-1}$. Average stroke rate $\left(S R_{\text {flume }}\right)$ was calculated on the basis of stroke cycles recorded during the 40 -second period by using a camcorder (JVC GC-PX100BE, Japan), working at the sampling rate of $100 \mathrm{~Hz}$. The observed number of cycles during the 40 seconds was converted to cycles $\cdot \min ^{-1}$. For each participant, 3 main parameters were calculated over the period of 40 seconds: (a) maximum value of force $-F_{a \max }[\mathrm{N}] ;(\mathrm{b})$ average value of force $-F_{a}$ ave $[\mathrm{N}]$; and (c) average impulse per cycle $-I_{a}[\mathrm{~N} \cdot \mathrm{s}]$ (calculated as the integral of force over a period of time

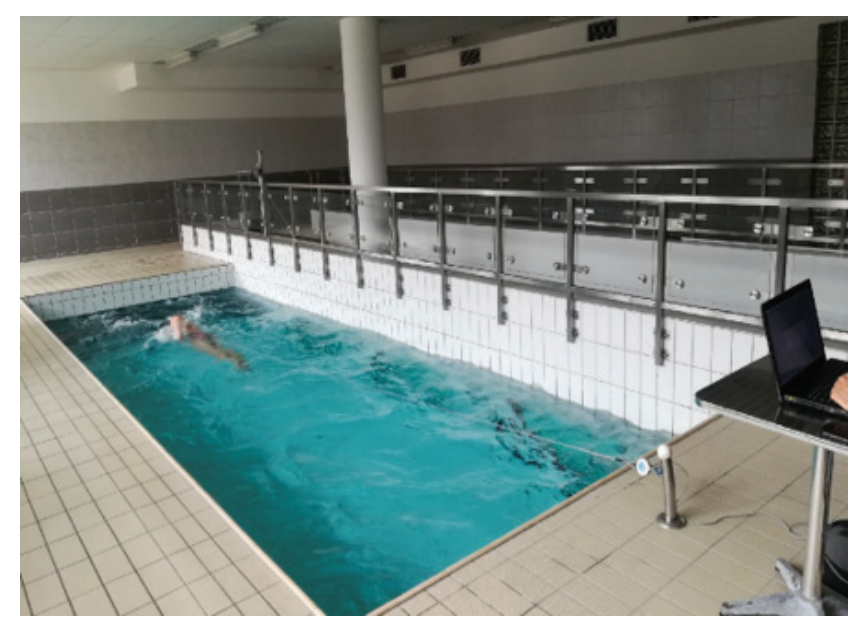

Fig. 1. Measurement of force during a 40-second all-out tethered front crawl arm stroking test 
containing all full cycles, which appeared during the 40 -second recording, divided by the number of these cycles $-n$ ):

$$
I_{a}=\frac{\int_{t_{0}}^{t_{1}} F d t}{n},
$$

where: $t_{0}$ - beginning of the first full cycle, $t_{1}$ - ending of the last full cycle in the 40 -second period.

In the lower extremity test, towing force was measured during tethered flutter kick (front crawl) in a pool over 40 seconds. The test was carried out with the support of a kickboard (Fig. 2). The steel cable attached to the swimmer during the test formed 2 equal $3-\mathrm{m}$ arms of a triangle. Such a triangular geometry of the measuring stand, instead of a single cable routed in the athlete's axis, was adopted to avoid collision of feet with the cable suspended just above them or a problem with lifting the lower body if the cable ran at a large angle. The cable end was attached to the start block, then passed through a grommet in the swimmer's belt, and, via a force transmitter, attached to another starting block. The distance between the fastening points on the starting blocks was $2.2 \mathrm{~m}$.

The swimmers were asked to swim towards the point visible in front of them, located in the axis of symmetry of the system. The geometry of the measuring system was the same for all swimmers, so the proportion of force registered by the force transducer $F_{\text {mes }}$ and the propulsion force generated by the subjects was also the same, in accordance with the formula:

$$
F=2 F_{\text {mes }} \cos \left[\arcsin \left(\frac{1.1}{3}\right)\right]=1.86 F_{\text {mes }}
$$

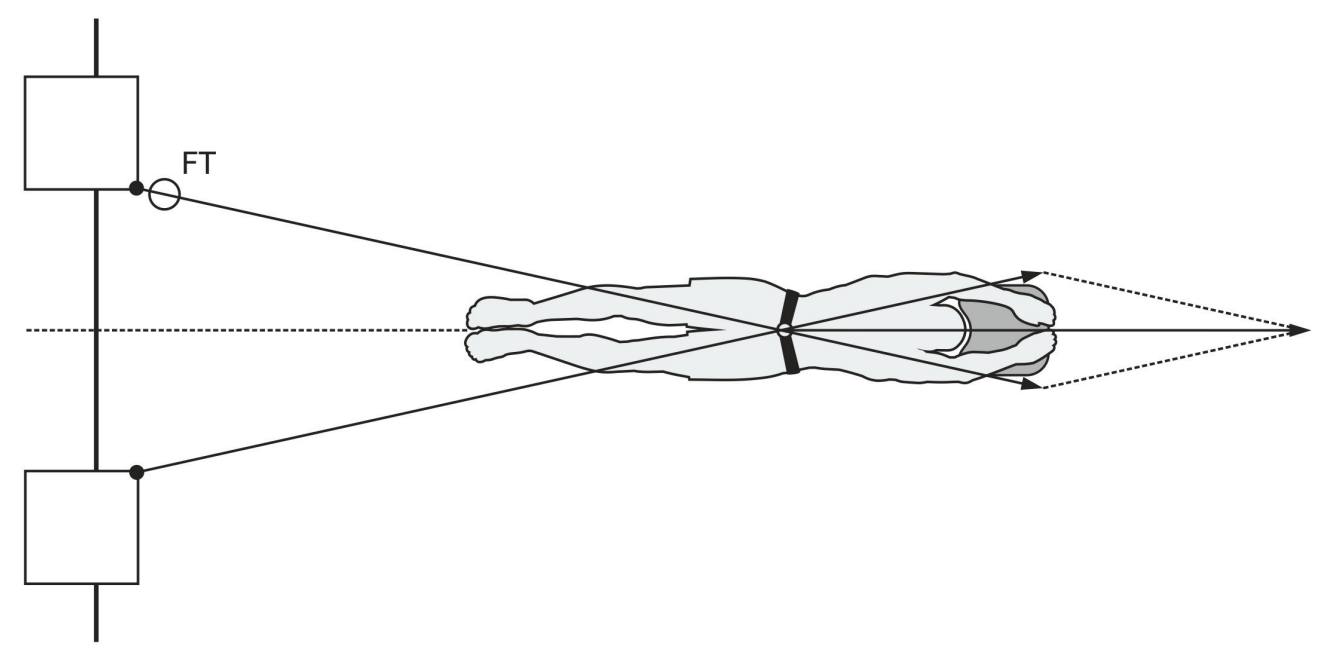

Fig. 2. Measurement of force during a 40-second all-out tethered flutter kick test (FT - force transmitter)
In this test, two main indices were calculated during the 40-second period: (a) maximum value of force $-F_{l \max }[\mathrm{N}]$; (b) average value of force $-F_{l \text { ave }}[\mathrm{N}]$.

The tethered front crawl tests were preceded by a warm-up selected by each participant, similar to the one carried out before a competition, including at least $1000-\mathrm{m}$ swimming with front crawl and other techniques.

The participants underwent familiarization with the tethered swimming before both tethered tests. Validation of the novel tethered swimming procedures was conducted; the intra-class correlation coefficient equalled 0.934 (95\% confidence interval: $0.736-0.985)$ for the upper extremity test and 0.957 (95\% confidence interval: $0.825-0.990)$ for the lower extremity test. Relative reliability was investigated by using intraclass correlation coefficient $(2,1)$ with $95 \%$ confidence interval. All recorded data were continuously displayed on a laptop screen and stored on a hard disk. The data were processed by signal processing software (Max 6.0; JBA, Poland) and filtered through a $4.5-\mathrm{Hz}$ low-pass filter.

\section{0-m front crawl trial}

The all-out 100-m front crawl trial was conducted in a $25-\mathrm{m}$ swimming pool that met the International Swimming Federation standards. Time measurement was performed by using an automatic timing device (Omega, Switzerland). In this race, the swimmers competed in pairs. Pairs were selected in accordance with the most similar best personal results. The participants were asked to perform in-water starts, which made it easier to shorten the underwater swimming phase after the start to $8 \mathrm{~m}$.

The surface stroke rate $-S R_{\text {surface }}$ [cycles $\cdot \mathrm{min}^{-1}$ ] - was determined by using 2 camcorders (JVC GC- 
-PX100BE, Japan) working at the sampling rate of $100 \mathrm{~Hz}$. One camcorder for each swimmer recorded his movements from the side view. The $S R_{\text {surface }}$ was taken as an average of 12 stroke cycles ( 3 consecutive cycles of the middle section in each of the 4 laps). The camcorders were placed in the middle $(12.5 \mathrm{~m})$ of the pool length and attached to tripods with a rotating head.

The stroke length $-S L$ - calculation was based on the data gathered in 9-m sectors of the distance of $100 \mathrm{~m}$, during 4 laps. For the purpose of this measurement, two other JVC GC-PX100BE camcorders (sampling rate: $100 \mathrm{~Hz}$ ) were used. The camcorders were located on tripods placed on the pool deck. Recordings from these 2 cameras were synchronized with a flash light triggered by the Omega electronic starting device. The JVC camcorders filmed each swimmer's head when it crossed the 8- and 17-m lines of each of the four 25-m laps.

The recordings allowed to calculate the average time needed to complete the 9-m sectors $(\Delta t)$ and thus to establish the average $36-\mathrm{m}$ surface swimming speed - $V_{\text {surface. }} S L$ was calculated as a quotient of the average speed for the 36-m and stroke rate $\left(S R_{\text {surface }}\right): S L=$ $V / S R_{\text {surface }}[\mathrm{m}]$. The sum of the start, turns and finish times was used to determine the 64-m average swimming speed $-V_{\text {STF. }}$. The swimming speed $\left(V_{\text {total1000 }}\right)$ was calculated from the total time taken by a swimmer to complete the $100-\mathrm{m}$ distance. The $100-\mathrm{m}$ free front crawl trial was preceded by a warm-up as before the tethered swimming tests.

\section{Statistical analyses}

The normality, homoscedasticity, and independency of the data assumptions were examined with the Kolmogorov-Smirnov, Levene, and Durbin-Watson tests, respectively. One-way repeated measures analysis of variance (ANOVA) and Tukey honestly significant difference (HSD) post-hoc tests were used to describe the comparison of average speeds ( $V_{\text {totall100, }}$ $\left.V_{\text {surface}}, V_{\text {STF }}\right)$. Pearson product-moment correlation coefficient was calculated between: (a) particular speeds $\left(V_{\text {total100}}, V_{\text {surface, }}, V_{\mathrm{STF}}\right)$ and all indices; (b) the predicted muscle mass of particular body parts and specific or general strength indices. To compare stroke rate data ( $S R$ of the 100-m free front crawl swimming and $S R$ of the tethered swimming), Student's $t$-test was applied for normally distributed data and equal variances. To further evaluate mean differences, Cohen's effect size (d) was calculated to express differences relative to the pooled standard deviation. The magnitude of differences between groups was expressed as standardized mean differences (Cohen's $d$, effect sizes). The criteria to interpret the effect size magnitude were as follows: trivial (0.00-0.19), small $(0.20-0.59)$, moderate $(0.60-1.20)$, and large (> 1.20). Additionally, Pearson linear relationship was computed between the separated speeds ( $\left.V_{\text {total100, }}, V_{\text {surface }}, V_{\mathrm{STF}}\right)$ of the $100-\mathrm{m}$ trial and between maximal and average force results of the tethered swimming. Statistical significance was set as $p \leq 0.05$. All tests were performed using the Statistica ver. 12 software (StatSoft, Inc.).

\section{Results}

The separated average speeds ( $V_{\text {total100 }}, V_{\text {surface, }}$, $\left.V_{\text {STF }}\right)$ of the 100-m front crawl trial were significantly different $\left(F_{2,50}=293.45 ; p<0.001\right)$. The Tukey HSD test revealed significant differences $(p<0.001)$ across the compared averages. Therefore, in the further assessment of the impact of particular indicators on swimming performance, we decided to make comparisons with each of these speeds separately (Fig. 3).

The computed Pearson product-moment correlation coefficients between indices of main body components showed a significant moderate or high relationship with swimming speeds only in the case of absolute values (Table 1).

The $m_{m}$ arms correlated strongly with general work and power indices of the arm-cranking test (Table 2), but there was no significant relationship when those indices were expressed per kilogram of BM. Further, it presented a moderate and large relationship with indices of tethered swimming with arms stroking only.

The relationship between $m_{m}$ legs and functional indices obtained in dry-land tests and tethered swimming with leg movement only (Table 3 ) showed significance only for the average value of absolute work in the 20 jumps $-W_{\text {CMJ }}[\mathrm{J}]$.

The data presented in Table 4 reflect a strong relationship between $m_{m \text { trunk }}$ and all absolute work and power indices of arms and legs obtained in dry-land tests.

The $m_{m}$ trunk revealed a relationship with strength indices of arms stroking only tethered swimming: $F_{a \max }, F_{a \text { ave }}$, and $I_{a}$. The $m_{m}$ trunk presented any significant relationship with propulsion strength indices of legs kicking only tethered swimming $\left(F_{l \text { max }}, F_{l \text { ave }}\right)$ (Table 5).

Correlations of swimming speeds with the predicted muscle mass of body segments and with absolute indices of arm-cranking and CMJ tests showed the most significant relationship between these speeds and $m_{m \text { trunk }}$ and $P_{\text {cra. }}$ A less significant relationship was 


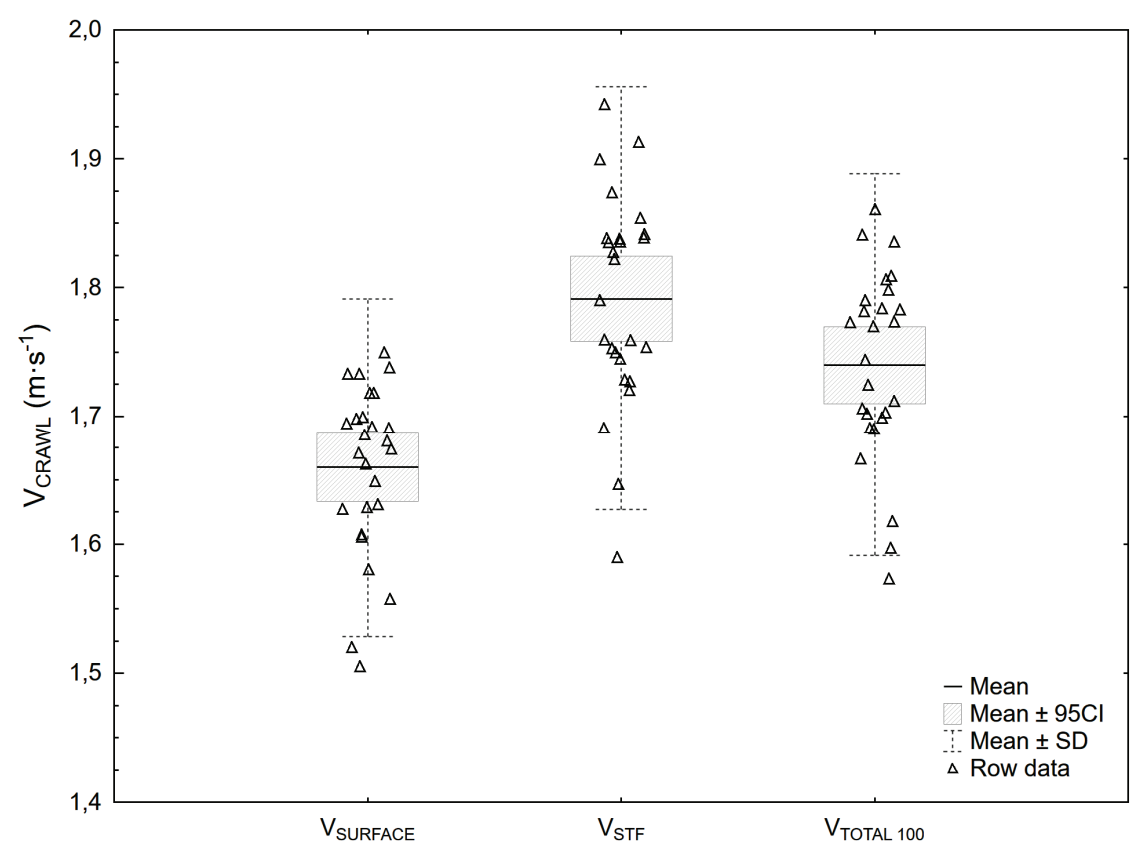

Fig. 3. Swimming speed in the $100-\mathrm{m}$ front crawl race $\left(V_{\text {total100 }}\right)$, in the zones of start, turn, and finish of the race $\left(V_{\mathrm{STF}}\right)$, and in its clear surface swimming $\left(V_{\text {surface }}\right)$

Table 1 . The indices of fat-free mass $(F F M), F F M$ as percentage of body mass, total body water $(T B W)$, and $T B W$ as percentage of body mass and their correlations with $V_{\text {surface, }} V_{\mathrm{STF}}$, and $V_{\text {total100 }}$

\begin{tabular}{|c|c|c|c|c|}
\hline Correlations & $\begin{array}{c}F F M[\mathrm{~kg}] \\
68.7 \pm 9.66\end{array}$ & $\begin{array}{c}F F M[\%] \\
88.9 \pm 3.54\end{array}$ & $\begin{array}{c}T B W[\mathrm{~kg}] \\
50.3 \pm 7.08\end{array}$ & $\begin{array}{c}T B W[\%] \\
65.1 \pm 2.59\end{array}$ \\
\hline$V_{\text {surface }}$ & $0.41^{*}$ & 0.16 & $0.42^{*}$ & 0.17 \\
\hline$V_{\text {STF }}$ & $0.53^{* *}$ & 0.14 & $0.53^{* *}$ & 0.15 \\
\hline$V_{\text {total100 }}$ & $0.50^{* *}$ & 0.15 & $0.50^{* *}$ & 0.16 \\
\hline
\end{tabular}

* significant relationship between the analysed indices with $p \leq 0.05$.

** significant relationship between the analysed indices with $p \leq 0.01$.

Table 2. Correlations of predicted muscle mass of arms ( $m_{m}$ arms $)$ with work and power indices of 40 -second arm-cranking test $\left(P_{\text {cra }}, P_{\text {cra rel }}, P_{\text {cra max }}, P_{\text {cra rel max }}\right)$ and with indices of arm stroking only tethered swimming $\left(F_{a \max }, F_{a \text { ave }}, I_{a}\right)$

\begin{tabular}{|c|c|c|c|c|c|c|c|}
\hline Correlations & $\begin{array}{c}P_{\text {cra }} \\
{[\mathrm{W}]} \\
377.7 \pm 51.45 \\
\end{array}$ & $\begin{array}{c}P_{\text {cra rel }} \\
{\left[\mathrm{W} \cdot \mathrm{kg}^{-1}\right]} \\
4.9 \pm 0.35 \\
\end{array}$ & $\begin{array}{c}P_{\text {cra max }} \\
{[\mathrm{W}]} \\
465.7 \pm 86.22 \\
\end{array}$ & $\begin{array}{c}P_{\text {cra rel max }} \\
{\left[\mathrm{W} \cdot \mathrm{kg}^{-1}\right]} \\
6.0 \pm 0.62 \\
\end{array}$ & $\begin{array}{c}F_{a \max } \\
{[\mathrm{N}]} \\
221.9 \pm 55.02\end{array}$ & $\begin{array}{c}F_{a \text { ave }} \\
{[\mathrm{N}]} \\
53.1 \pm 7.90 \\
\end{array}$ & $\begin{array}{c}I_{a} \\
{[\mathrm{~N} \cdot \mathrm{s}]} \\
59.0 \pm 8.83 \\
\end{array}$ \\
\hline $\begin{array}{c}m_{m \text { arms }}[\mathrm{kg}] \\
7.4 \pm 1.37\end{array}$ & $0.79 * *$ & 0.03 & $0.79 * *$ & 0.35 & $0.44^{*}$ & $0.52 * *$ & $0.73 * *$ \\
\hline
\end{tabular}

* significant relationship between the analysed indices with $p \leq 0.05$.

** significant relationship between the analysed indices with $p \leq 0.01$.

Table 3. Correlations of predicted muscle mass of legs $\left(m_{m}\right.$ legs $)$ with functional indices of $20 \mathrm{CMJ}$ test $\left(h, W_{\mathrm{CMJ}}\right)$

and indices of leg kicking only tethered swimming $\left(F_{l \max }, F_{l \text { ave }}\right)$

\begin{tabular}{|c|c|c|c|c|}
\hline Correlations & $\begin{array}{c}h[\mathrm{~cm}] \\
35.2 \pm 3.73\end{array}$ & $\begin{array}{c}W_{\mathrm{CMJ}}[\mathrm{J}] \\
258.8 \pm 41.75\end{array}$ & $\begin{array}{c}F_{l \max }[\mathrm{N}] \\
153.5 \pm 31.04\end{array}$ & $\begin{array}{c}F_{l \text { ave }}[\mathrm{N}] \\
48.0 \pm 6.43\end{array}$ \\
\hline $\begin{array}{l}m_{m \text { legs }}[\mathrm{kg}] \\
21.9 \pm 2.73\end{array}$ & -0.05 & $0.69 * *$ & 0.08 & 0.22 \\
\hline
\end{tabular}

** significant relationship between the analysed indices with $p \leq 0.01$. 
observed in the case of $m_{m}$ arms and $m_{m}$ legs (not significant for $\left.V_{\text {surface }}\right)$. The correlation with $W_{\mathrm{CMJ}}$ was not significant at all speeds (Table 6).

Among the indices obtained in tethered swimming tests, the following significant predictors of swimming speed were found: $I_{a}$ with $V_{\text {total100 }}$ and $V_{\mathrm{STF}}$, and $F_{l \text { max }}$ also with $V_{\text {total100 }}$ and $V_{\mathrm{STF}}$. The relationship between $F_{l \text { ave }}$ and $V_{\text {STF }}$ was close to significant (Table 7).

In this study, the basic stroke kinematic indices: $S R_{\text {surface }}$ of $46.5 \pm 3.99$ cycles $\cdot \mathrm{min}^{-1}$ or $S L$ of 2.16 $\pm 0.18 \mathrm{~m}$ in front crawl swimming did not significantly influence the $V_{\text {surface. }} S R_{\text {flume }}$ calculated for tethered arms only front crawl swimming $\left(53.6 \pm 3.52\right.$ cycles $\left.\cdot \min ^{-1}\right)$ was significantly different in comparison with $S R_{\text {surface }}$ (paired $t$-test: $t_{(25)}=8.55 ; p<0.001$ ); also, the calculation of the Cohen's effect size to assess magnitude of difference indicated a large effect size $(d=1.976)$.

\section{Discussion}

In the present study, FFM and TBW as absolute, total body composition indicators turned out valid predictors of best performance in 100-m front crawl trial. This was in accordance with general conclusions of other studies [16], [18]. Further valuable findings were strong relationships between arm and trunk muscle masses $\left(m_{m}\right.$ arms, $\left.m_{m \text { trunk }}\right)$ and dry-land test results $\left(P_{\text {cra }}, P_{\text {cra } \max }\right)$, as well as the results of the tethered swimming test with arm propulsion $\left(F_{a \max }, F_{a \text { ave }}, I_{a}\right)$. Muscle masses of these segments also correlated with $V_{\text {STF }}$ and $V_{\text {total100, }}$, and also with $V_{\text {surface }}$ ( $m_{m \text { trunk }}$ only).

There is a limited amount of published information on the morphological shape or favourable muscle distribution in swimmers in relation to swimming

Table 4. Correlations of predicted muscle mass of trunk ( $\left.m_{m \text { trunk }}\right)$ with work and power indices of 40 -second arm-cranking test $\left(P_{\text {cra }}, P_{\text {cra rel }}, P_{\text {cra max }}, P_{\text {cra rel max }}\right)$ and with functional indices of $20 \mathrm{CMJ}$ test $\left(h, W_{\mathrm{CMJ}}\right)$

\begin{tabular}{|c|c|c|c|c|c|c|}
\hline Correlations & $P_{\text {cra }}[\mathrm{W}]$ & $\begin{array}{c}P_{\text {cra rel }} \\
{\left[\mathrm{W} \cdot \mathrm{kg}^{-1}\right]}\end{array}$ & $P_{\text {cra max }}[\mathrm{W}]$ & $\begin{array}{c}P_{\text {cra rel max }} \\
{\left[\mathrm{W} \cdot \mathrm{kg}^{-1}\right]}\end{array}$ & $h[\mathrm{~cm}]$ & $W_{\mathrm{CMJ}}[\mathrm{J}]$ \\
\hline $\begin{array}{l}m_{m \text { trunk }}[\mathrm{kg}] \\
36.2 \pm 5.08\end{array}$ & $0.86^{* *}$ & 0.01 & $0.86^{* *}$ & $0.37(p=0.06)$ & -0.02 & $0.71^{* *}$ \\
\hline
\end{tabular}

** significant relationship between the analysed indices with $p \leq 0.01$.

Table 5. Correlations of predicted muscle mass of trunk ( $\left.m_{m \text { trunk }}\right)$ with indices of arm stroking only tethered swimming $\left(F_{a \max }, F_{a \text { ave }}, I_{a}\right)$ and indices of leg kicking only tethered swimming $\left(F_{l \max }, F_{l \text { ave }}\right)$

\begin{tabular}{|c|c|c|c|c|c|}
\hline Correlations & $F_{a \max }[\mathrm{N}]$ & $F_{a \text { ave }}[\mathrm{N}]$ & $I_{a}[\mathrm{~N} \cdot \mathrm{s}]$ & $F_{l \max }[\mathrm{N}]$ & $F_{l \text { ave }}[\mathrm{N}]$ \\
\hline$m_{m \text { trunk }}[\mathrm{kg}]$ & $0.54^{* *}$ & $0.47^{*}$ & $0.64 * *$ & 0.16 & 0.33 \\
\hline
\end{tabular}

* significant relationship between the analysed indices with $p \leq 0.05$.

** significant relationship between the analysed indices with $p \leq 0.01$.

Table 6. Correlations of $m_{m \text { arms }}, m_{m \text { legs }}, m_{m \text { trunk }}$, and absolute indices of arm-cranking and CMJ tests with $V_{\text {surface, }} V_{\mathrm{STF}}$, and $V_{\text {total100 }}$

\begin{tabular}{|c|c|c|c|c|c|c|}
\hline Correlations & $m_{m \text { arms }}$ & $m_{m \text { legs }}$ & $m_{m \text { trunk }}$ & $P_{\text {cra }}[\mathrm{J}]$ & $P_{\text {cra max }}[\mathrm{W}]$ & $W_{C M J}[\mathrm{~J}]$ \\
\hline$V_{\text {surface }}$ & 0.34 & $0.38(p=0.05)$ & $0.44^{*}$ & $0.39^{*}$ & 0.31 & 0.17 \\
\hline$V_{\text {STF }}$ & $0.45^{*}$ & $0.47^{*}$ & $0.57^{* *}$ & $0.51^{*}$ & $0.42^{*}$ & $0.36(p=0.07)$ \\
\hline$V_{\text {total100 }}$ & $0.42^{*}$ & $0.44^{*}$ & $0.54^{* *}$ & $0.48^{*}$ & $0.39^{*}$ & 0.30 \\
\hline
\end{tabular}

* significant relationship between the analysed indices with $p \leq 0.05$

** significant relationship between the analysed indices with $p \leq 0.01$.

Table 7. Correlations of tethered swimming indices $\left(F_{a \max }, F_{a \text { ave }}, I_{a}, F_{l \max }, F_{l \text { ave }}\right)$ with $V_{\text {surface }}, V_{\mathrm{STF}}$, and $V_{\text {total100 }}$

\begin{tabular}{|c|c|c|c|c|c|}
\hline Correlations & $F_{a \max }[\mathrm{N}]$ & $F_{a \text { ave }}[\mathrm{N}]$ & $I_{a}[\mathrm{~N} \cdot \mathrm{s}]$ & $F_{l \max }[\mathrm{N}]$ & $F_{l \text { ave }}[\mathrm{N}]$ \\
\hline$V_{\text {surface }}$ & 0.23 & 0.23 & 0.34 & 0.33 & 0.26 \\
\hline$V_{\text {STF }}$ & 0.35 & 0.34 & $0.43^{*}$ & $0.42^{*}$ & $0.37(p=0.06)$ \\
\hline$V_{\text {total100 }}$ & 0.31 & 0.31 & $0.41^{*}$ & $0.40^{*}$ & 0.34 \\
\hline
\end{tabular}

* significant relationship between the analysed indices with $p \leq 0.05$. 
performance. Searching for previous reports with similar results, we found a study by Grimston and Hay [7], performed among college swimmers. The authors showed that in front crawl arm stroking, muscles of the axilla region, i.e., shoulder extensors (the sternocostal part of pectoralis major, latissimus dorsi, and teres major), were most useful in the propulsion phase of swimming. They implied that the cross-sectional area of these muscles could be an indicator of propulsion efficiency in short and long front crawl events. Moreover, an increased size of the axillary muscles involved in the propulsive phase should lead to greater force generation. In a more recent study by Nasirzade et al. [13], carried out on young male swimmers, a significant relationship was found between muscle architectural characteristics, such as muscle thickness and the fascicle length of triceps brachii, and 200-m front crawl swimming performance. Furthermore, the triceps brachii fascicle length was one of the best predictors of performance (beside $S L$ and body height).

Our results were also consistent with other studies concerning young male swimmers, in which arm muscle cross-sectional area turned out strongly correlated with propulsive force and was used in an equation to estimate propulsive force [2], [19].

It is probably well recognized today that in sprint front crawl [4], [7]-[8], it is a priority to reach respective body length and, by training, adequate athleticism and muscle mass distribution should be expanded. Those physical traits should be accountable for propulsion generation in the given swimming stroke. It is challenging in the coaching process because maintaining adequate body slenderness is needed as well, but it can also be achieved by a reduction of skinfolds during the course of the season [8], [16]. Considering the BMI, it could be advisable to compare the results of our group (mean BMI of 22.78) with those of other elite athletes (Olympic freestyle swimmers: mean BMI of 22.98) [4]. One can state that there was still space to fill with muscle mass towards the expansion of the mesomorphic body component with simultaneous reduction of adipose tissue, whose level was $11.1 \%$.

In our study, $m_{m}$ legs was strongly correlated with the ability of the lower limbs to perform work, measured in $20 \mathrm{CMJ}$, but $m_{m}$ legs did not influence the results obtained in tethered swimming with leg kicking. Thus, $m_{m}$ legs plays a major role in pushing away from the wall rather than in surface swimming ( $\left.V_{\text {surface }}\right)$, which remains in line with other observations [3], [25]. As we mentioned in the introduction, in the front crawl, the economics of propulsion generation with legs is much lower than with arms. This is due to the trajectory of the movement and to the mass of the lower limbs over 3 times higher than that of the upper extremities, which consume less energy than legs, producing similar propulsive movements [27]. Nevertheless, leg movement plays an important role in sprint front crawl because, as confirmed by previous research, it is valid for body stabilization [24], [26]. Further, it should be taken into account that the propulsive role of the flutter-kick decreases as the swimming velocity rises [5]. On the other hand, increasing the freestyle competition distance-time ratio means that swimmers search for energy saving. This causes the need to trade-off between less energy consuming arm stroking and higher energy expenditure with intensive leg flutter kicks. The choice is noticeable through a limited count of kicks per arm cycle, reduced kick amplitude, or almost towing the legs.

The arm-cranking test indicators $\left(P_{\text {cra }}\right.$ and $\left.P_{\text {cra max }}\right)$ were better predictors of swimming results than $W_{\mathrm{CMJ}}$ owing to their higher relationship (moderate and significant) with particular swimming speeds and very strong relationship with $m_{m}$ arms and $m_{m}$ trunk. This is consistent with other study [9], in which the anaerobic ability to generate muscle power, measured in an armcranking test, correlated well with sprint front crawl swimming results.

The $F_{l \text { max }}$ was a significant in-water-specific predictor of $V_{\text {total100 }}$ and $V_{\text {STF. }}$. We expected a greater impact of $F_{l \text { ave }}$ on swimming speed, but this relationship turned out slightly lower. These findings are similar to those recorded by Vorontsov, Dyrco, Binevsky, and Solomatin [22] or Morouço et al. [12]. Nevertheless, they are generally in agreement with the results of a study by Shimonagata et al. [20], who suggested that maximum swimming power and endurance ability were the most important factors for estimating a 100-m freestyle performance. Papoti et al. [15] stated that physiologically, most performance gains in 200-m front crawl performance were related to anaerobic conditioning, and the main predictor was the mean force of 30 -second maximal effort of front crawl tethered swimming.

In the tethered swimming test with arms, only $I_{a}$ influenced the $V_{\text {total100 }}$ and $V_{\mathrm{STF}}$ results. It is a relationship that shows an above-average capability to anaerobically generate propulsion force that the swimmer applies, but its most effective use depends on the ability to properly adjust the number of arm cycle movements $\left(S R_{\text {flume }}\right) . S R_{\text {flume }}$ was significantly higher than $S R_{\text {surface }}$ This was due to the lack of flutter kick, which would support upper body stroking [5], [24].

This study indicates that muscle mass development, in appropriate proportion to the size of the body, enables the sportsmen to generate maximal propulsion 
force in front crawl sprint swimming. It is worth emphasizing the significant impact of the $m_{m}$ trunk on swimming results, which turned out to be greater than that of $m_{m}$ arms and $m_{m}$ legs. Here, in conclusion, we should mention that absolute dry-land anaerobic 40 -second strength indices of arm cranking $-P_{\text {cra }}$ and $P_{\text {cra max }}$ - were a good complement to the specific inwater assessment of power and endurance properties. The dependence of $W_{\mathrm{CMJ}}$ and $F_{l \text { ave }}$ indices on $V_{\mathrm{STF}}$ (close to significance) at least partly alludes to a positive relationship with swimming speed observed during start and turn performances [3], [25].

The present study concludes that in somatically well-shaped swimmers, the predicted muscle mass of trunk and limbs is strongly and moderately associated with dry-land and in-water anaerobic strength, respectively, and these general and specific strength abilities significantly influence $100-\mathrm{m}$ front crawl swimming performance.

\section{Conclusions}

The development of the desired muscle mass should concern parts of the body most related to the production of propulsion force. In front crawl swimming, this applies especially to the trunk and arms. The possessed muscle mass should enable effective generation of propulsion force and harmonize with the slenderness of the body. This study demonstrates that the prediction of front crawl 100-m performance on the basis of strength, measured in dry-land and inwater conditions, can be well complemented by the measurement of somatic traits, such as muscle mass.

\section{References}

[1] Barbosa A.C., Valadẽo P.F., Wilke C.F., Martins F. De S., Silva D.C.P., Volkers S.A., Lima C.O.V., Ribeiro J.R.C., BITTENCOURT N.F., BARROSO R., The road to 21 seconds: A case report of a 2016 Olympic swimming sprinter, Int. J. Sport. Sci. Coach., 2019, 14, 393-405.

[2] Cochrane K.C., Housh T.J., Smith C.M., Hill E.C., Jenkins N.D.M., Johnson G.O., Housh D.J., Schmidt R.J., CRAMER J.T., Relative contributions of strength, anthropometric, and body composition characteristics to estimated propulsive force in young male swimmers, J. Strength Cond. Res., 2015, 29, 1473-1479.

[3] Cronin J., Jones J., Frost D., The relationship between dryland power measures and tumble turn velocity in elite swimmers, J. Swim. Res., 2007, 17, 17-23.

[4] Gagnon C.M., SteIPER M.E., Pontzer H., Elite swimmers do not exhibit a body mass index trade-off across a wide range of event distances, Proc. R. Soc. B Biol. Sci., 2018, 285, 2-6.
[5] Gatta G., Cortesi M., Di Michele R., Power production of the lower limbs in flutter-kick swimming, Sport. Biomech., 2012, 11, 480-491.

[6] Gourgoulis V., Boli A., Aggeloussis N., Toubekis A., Antoniou P., Kasimatis P., Vezos N., Michalopoulou M., Kambas A., MaVRomatis G., The effect of leg kick on sprint front crawl swimming, J. Sports Sci., 2014, 32, 278-289.

[7] GRIMSTON S.K., HAY J.G., Relationships among anthropometric and stroking characteristics of college swimmers, Med. Sci. Sports Exerc., 1986, 18, 60-8.

[8] Hawes M.R., SovaK D., Morphological prototypes, assessment and change in elite athletes, J. Sports Sci., 1994, 12, 235-242.

[9] Hawley J.A., Williams M.M., Relationship between upper body anaerobic power and freestyle swimming performance, Int. J. Sports Med., 1991, 12, 1-5.

[10] Mitchell L.J.G., Rattray B., Saunders P.U., Pyne D.B., The relationship between talent identification testing parameters and performance in elite junior swimmers, J. Sci. Med. Sport, 2018, 21, 1281-1285.

[11] Morouço P.G., Marinho D.A., Izquierdo M., Neiva H., MARQUES M.C., Relative contribution of arms and legs in front crawl tethered swimming, according to gender, Biomed. Res. Int., 2015, 563206, 1-6.

[12] Morouço P.G., NeIVA H., GonZÁlez-Badillo J.J., GarRido N., Marinho D.A., MARQues M.C., Associations between dry land strength and power measurements with swimming performance in elite athletes: a pilot study, J. Hum. Kinet., 2011, 105-112.

[13] Nasirzade A., Sadeghi H., Sobhkhiz A., Mohammadian K., Nikouei A., BaghaiYan M., FAtTAHI A., Multivariate analysis of 200-m front crawl swimming performance in young male swimmers, Acta Bioeng. Biomech., 2015, 17, 137-143.

[14] NG F., Wen Yam J., Lum D., BARBosa T.M., Human thrust in aquatic environment: The effect of post-activation potentiation on flutter kick, J. Adv. Res., 2019, 21, 65-70.

[15] Papoti M., Martins L.E.B., Cunha S.A., Zagatto A.M., GoBAтTO C.A., Effects of taper on swimming force and swimmer performance after an experimental ten-week training program, J. Strength Cond. Res., 2007, 21, 538-542.

[16] Pyne D.B., Anderson M.E., Hopkins W.G., Monitoring changes in lean mass of elite male and female swimmers, Int. J. Sports Physiol. Perform., 2006, 1, 14-26.

[17] Rejman M., Tyc Ł., Kociuba M., Bornikowska A., Rudnik D., KozIEŁ S., Anthropometric predispositions for swimming from the perspective of biomechanics, Acta Bioeng. Biomech., 2018, 20, 151-159.

[18] Roelofs E.J., SMith-Ryan A.E., TreXler E.T., Hirsch K.R., Seasonal effects on body composition, muscle characteristics, and performance of collegiate swimmers and divers, J. Athl. Train., 2017, 52, 45-50.

[19] Santos M., Junior M., Melo Wv., Costa A., Costa M., Estimate of propulsive force in front crawl swimming in young athletes, Open Access J. Sport. Med., 2012, 3, 115-120.

[20] Shimonagata S., Taguchi M., Miura M., Effect of swimming power, swimming power endurance and dryland power on $100 \mathrm{~m}$ freestyle performance, Biomech. Med. Swim. IX, 2003, 391-396.

[21] Stager J.M., Coyle M.A., Energy Systems, [in:] Handbook of Sports Medicine and Science: Swimming, ed. Blackwell Science, Ltd., Oxford 2005, 1-19.

[22] Vorontsov A.R., Dyrco V.V., Binevsky D.A., SOlOMATIN V.R., Patterns of growth for some characteris- 
tics of physical development, functional and motor abilities in boy-swimmers 11-18 years, Biomechanics and Medicine in Swimming VIII. eds. K.L. Keskinen, P.V. Komi, A.P. Hollander, University of Jyväskylä, Jyväskylä 1999, 327-335.

[23] WĄDrzyk Ł., Staszkiewicz R., KRYst Ł., ŻEgleń M., Gender effect on underwater undulatory swimming technique of young competitive swimmers, Acta Bioeng. Biomech., 2019, $21,3-11$

[24] WatKins J., GoRdon A.T., The effect of leg action on performance in the sprint front crawl stroke, Biomech. Med. Swim., 1982, 310-314.
[25] West D.J., Owen N.J., Cunningham D.J., Cook C.J., KILDUFF L.P., Strength and power predictors of swimming starts in international sprint swimmers, J. Strength Cond. Res., 2011, 25, 950-955.

[26] YANAI T., WiLSON B.D., How does buoyancy influence frontcrawl performance? Exploring the assumptions, Sport. Technol., 2008, 1, 89-99.

[27] ZATSIORSKY V.M., International Federation of Sports Medicine, IOC Medical Commission: Biomechanics in sport: performance enhancement and injury prevention, Blackwell Science, 2000. 